\title{
QUEBRA DA DORMÊNCIA DE SEMENTES DE QUATRO LEGUMINOSAS ARBÓREAS
}

\author{
Maria do P. Socorro C. Bona do Nascimento ${ }^{1}$ \\ Maria Edileide Alencar Oliveira'
}

Recebido em 29/10/1997. Aceito em 27/04/1999

\begin{abstract}
RESUMO - (Quebra da dormência de sementes de quatro leguminosas arbóreas). Nas sementes de leguminosas é comum a ocorrência de dormência devido à dureza do tegumento. Sementes de bordão-de-velho (Samanea saman (Jacq.) Merr.), angico-de-bezerro (Piptadenia moniliformis Benth.), pau-ferro (Caesalpinia ferrea Mart. ex. Tul.) e sabiá (Mimosa caesalpiniifolia Benth.) foram submetidas aos seguintes tratamentos: escarificação com lixa, água a $80^{\circ} \mathrm{C}$ por 1,0; 2,5 e 5,0min; água à temperatura ambiente (12;24 e 48h); ácido sulfúrico concentrado (1;5 e $\left.10 \mathrm{~min}\right) \mathrm{e}$ álcool etílico (5; 10 e $25 \mathrm{~min})$, visando a quebra da dormência. De sabiá foram testados os artículos e as sementes nuas. Usou-se o delineamento inteiramente ao acaso, com quatro repetiçōes (50 sementes/repetição). Os tratamentos com ácido sulfúrico resultaram em maiores percentuais de germinação para bordão-de-velho $(98,5-99,0 \%)$ e para pau-ferro $(76,5-89,0 \%)$. Para angico-de-bezerro, destacaram-se água a $80^{\circ} \mathrm{C}$ durante 1,0 ou $2,5 \mathrm{~min}$, e ácido durante $10 \mathrm{~min}(82,5$; 74,0 e $87,0 \%$ de germinação, respectivamente). Maiores percentagens de germinação foram obtidas nas sementes nuas de sabiá do que nos artículos, destacando-se, com germinação de 73,0 a $93,5 \%$, os tratamentos com água a $80^{\circ} \mathrm{C}$, com ácido 5 e $10 \mathrm{~min}$, e com álcool etílico por $5 \mathrm{~min}$. Considerando-se o custo e os ríscos na utilização do ácido sulfúrico, é preferível, para quebrar a dormência das sementes estudadas, a utilizaçâo dos tratamentos com água a $80^{\circ} \mathrm{C}$, ainda que seja necessário aumento na densidade de semeadura.
\end{abstract}

Palavras-chaves - Caesalpinia ferrea, Mimosa caesalpiniifolia, Piptadenia moniliformis, Samanea saman, germinação

ABSTRACT - (Breaking the hard seed coat dormancy of four legume tree seeds). In legume seeds dormancy imposed by the hard seed coat is common. Seeds of four legumes, Samanea saman (Jacq.) Merr., Piptadenia moniliformis Benth., Caesalpinia ferrea Mart. ex. Tul., and Mimosa caesalpiniifolia Benth. were scarified with sand paper; hot water $\left(80^{\circ} \mathrm{C}\right)$ for $1,2.5$ and $5.0 \mathrm{~min}$; water at room temperature for 12,24 and $48 \mathrm{~h}$; concentrated sulphuric acid for 1,5 and 10 $\mathrm{min}$; and in ethilic alcohol for 5,10 and $25 \mathrm{~min}$, to break seed coat dormancy. In $M$. caesalpiniifolia the treatments were applied to both articule and naked seeds. A completely randomized experimental design with four replications ( 50 seeds/ replication) was used. The treatments with sulfuric acid were the most effective on S. saman (98.5-99.0\% germination) and C. ferrea $(76.5-89 \%)$. For P. moniliformis, germination was best achieved after the application of hot water (1 or 2.5 $\mathrm{min})$ and sulphuric acid during $10 \mathrm{~min}(82.5,74$ and $87 \%$ germination, respectively). For $M$. caesalpiniifolia, the results with naked seeds were better than with articules, the hot water, sulphuric acid ( 5 and $10 \mathrm{~min})$, and ethilic alcohol ( $5 \mathrm{~min}$ ) treatments being especially effective, with germination ranging from $73 \%$ to $93.5 \%$. Due to the costs and risks when using sulphuric acid, it would be recommended the use of hot water treatments, even if some increase in sowing density
becomes necessary.

Key words - Caesalpinia ferrea, Mimosa caesalpiniifolia, Piptadenia moniliformis, Samanea saman, germination

${ }^{1}$ EMBRAPA, Centro de Pesquisa Agropecuária do Meio-Norte , CPAMN, C. Postal 01, CEP 64.006-220, Teresina, PI, Brasil 


\section{Introdução}

Na família Leguminosae, a dormência causada pela impermeabilidade do tegumento é comum, constituindo, possivelmente, o único tipo de dormência presente na família (Bewley \& Black 1994). Para promover ranhuras ou romper o tegumento das sementes, possibilitando a penetração de água, alguns tratamentos têm sido comumente usados.

Monte et al. (1995) verificaram que a germinação das sementes de fava d'anta (Dimorphandra gardneriana Tul.) aumentou de $0 \%$ para 93\% após o tratamento com ácido sulfúrico. Outros autores (Sabiiti 1983; Rodrigues et al. 1990; Kondo 1993; Dutra et al. 1994) também obtiveram grandes incrementos na percentagem de germinação após tratarem sementes de diversas leguminosas com ácido sulfúrico. Demel \& Demel (1994), apesar de apontarem este ácido como tratamento eficaz para a quebra da dormência de Erythrina burana, desaconselharam a sua utilização, recomendando a busca de método mais barato, seguro, conveniente e rápido.

A água quente também tem sido usada visando a quebra de dormência das sementes, mas os resultados têm sido contraditórios (Rodrigues et al. 1990). Skerman (1977) cita resultados de vários autores favoráveis à utilização de água quente, recomendando este tratamento para sementes de Leucaena leucocephala, Stylosanthes guianensis, Pueraria javanica, Glycine wightii, dentre outras leguminosas.

Barbosa et al. (1996), ao estudarem a germinação de nove leguminosas da caatinga, verificaram que a escarificação com lixa foi o método mais eficiente para promover a germinação das sementes de Macroptilum lathyroides, M. bracteatum e Cratylia mollis. No entanto, pelo elevado dispêndio de trabalho, este método é indicado apenas para o caso de pequenas quantidades de sementes (Antônio et al. 1985).

A quebra da dormência, além do incremento da percentagem de germinação, tem a vantagem de aumentar-lhe a velocidade, resultando em maior uniformidade inicial da população e maior chance de sobrevivência.
O presente trabalho teve como objetivo estudar a germinação das sementes de quatro leguminosas arbóreas, visando identificar tratamentos que resultem em maior percentual de germinação.

\section{Material e métodos}

As espécies estudadas foram: bordão-develho (Samanea saman (Jacq.) Merr.), angico-debezerro (Piptadenia moniliformis Benth.), pauferro (Caesalpinia ferrea Mart. ex. Tul.) e sabiá (Mimosa caesalpiniifolia Benth.), sendo as sementes submetidas aos seguintes tratamentos: ausência de escarificação (testemunha); escarificação com lixa; imersão em água a $80^{\circ} \mathrm{C}$ durante 1; 2,5 e $5 \mathrm{~min}$; imersão em água à temperatura ambiente $27^{\circ} \mathrm{C}$ durante $12 ; 24$ e 48 h; imersão em ácido sulfúrico concentrado durante $1 ; 5$ e $10 \mathrm{~min}$ e imersão em álcool etílico durante $5 ; 10$ e $25 \mathrm{~min}$ Nos tratamentos com água quente e água à temperatura ambiente, a quantidade de água utilizada foi de quatro vezes o volume das sementes; de ácido e álcool utilizaram-se duas vezes o volume das sementes.

Cada espécie constituiu um ensaio diferente. As sementes foram colhidas dois meses antes do início dos experimentos e foram colocadas para germinar logo após a aplicação dos tratamentos. Preliminarmente, foi feita a aplicação de produto à base de benomyl 50\%, em dosagem equivalente a $100 \mathrm{~g}$ do produto comercial por $100 \mathrm{~kg}$ de sementes. Os frutos de sabiá são indeiscentes e apresentam grande dificuldade para a retirada das sementes do interior dos artículos (segmento do fruto, contendo uma semente), por isso procedeuse o teste em sementes nuas e com o artículo integral.

O delineamento experimental utilizado foi o inteiramente casualizado, com quatro repetições, sendo cada parcela constituída por uma caixa de germinação contendo 50 sementes, colocadas sobre três camadas de papel de filtro umedecido. As caixas de germinação foram colocadas em germinador com temperatura constante de $28 \pm$ $2^{\circ} \mathrm{C}$. O germinador, modelo Biomatic, não tinha luz própria, e recebia a iluminação ambiente através da porta e da parte superior, ambas de 
vidro. No interior do germinador, a luminosidade média era cerca de 100 lux durante dez horas/dia. Durante a noite, a sala permanecia sem iluminação.

A partir do primeiro e até ao $15^{\circ}$ dia, foram realizadas observações diárias de ocorrência de germinação, anotando-se e descartando-se as sementes germinadas. As caixas de germinação recebiam a aplicação de água destilada, na forma de spray, sempre que necessário, visando manter a umidade uniforme e sem acúmulo de água. Uma semente era considerada germinada mediante a verificação da protrusão da radícula, a partir de $1 \mathrm{~mm}$ (Bewley \& Black 1994). A velocidade de germinação foi calculada segundo Popinigis (1977).

Para a análise de variância, os dados foram transformados em arco seno $\sqrt{\%} \mathrm{e}$ as médias foram comparadas pelo teste de Tukey a 5\%.

\section{Resultados e discussão}

Todas as espécies estudadas apresentaram elevado grau de dormência, conforme indicado pela baixa percentagem de germinação das testemunhas (Tab. 1).

Para as sementes de bordão-de-velho, cuja germinação na testemunha foi de apenas $0,5 \%$ (Tab. 1), o único tratamento eficaz para a quebra da dormência das sementes foi a imersão em ácido sulfúrico concentrado, sendo os três tempos testados, $1 ; 5$ e $10 \mathrm{~min}$, semelhantes entre si, com germinação variando de 98,5 a $99,0 \%$. Os dados obtidos no presente trabalho não confirmaram as indicações de Withington (fide Shelton 1994), relacionando água quente e imersão em água à temperatura ambiente como tratamentos recomendados para aumentar a percentagem de germinação das sementes de bordão-de-velho. A espécie apresentou elevada dormência, com apenas $0,5 \%$ de germinação na testemunha. Considerando-se os riscos da utilização do ácido sulfúrico, apesar da sua eficiência, deverão ser buscados outros métodos para quebrar a dormência das sementes de bordão-de-velho.

Para as sementes de pau-ferro, a imersão em ácido sulfúrico concentrado também foi o tratamento que resultou em maior percentagem de germinação. Tal como nas sementes de bordãode-velho, não houve diferença entre os períodos de imersão testados, cujas percentagens de germinação variaram de 76,5 a $89,0 \%$. Este resultado está de acordo com os obtidos por Duarte (1978), Dutra et al. (1994) e Souto (1996) que obtiveram de $82 \%$ a $90 \%$ de germinação em sementes de pau-ferro, após a escarificação com ácido sulfúrico. O segundo melhor tratamento foi

Tabela 1 - Percentagem de germinação das sementes de Leguminosas ao final de 15 dias de teste.

\begin{tabular}{|c|c|c|c|c|c|}
\hline Tratamentos & Angico-de-bezerro & Bordão-de-velho & Pau-ferro & Sabiá (artículo) & Sabiá (semente nua) \\
\hline Testemunha & 5,5 ef & $0,5 \mathrm{c}$ & $10,5 \mathrm{e}$ & $31,5 \mathrm{ab}$ & 38,0 def \\
\hline Lixa $22,0 \mathrm{~cd}$ & $7,0 \mathrm{~b}$ & 14,5 cde & $26,5 \mathrm{ab}$ & 66,5 bcde & \\
\hline \multicolumn{6}{|l|}{ Água $80^{\circ} \mathrm{C}$} \\
\hline $5 \mathrm{~min}$ & 20,5 cde & $0,5 \mathrm{c}$ & $9,5 \mathrm{e}$ & $38,0 \mathrm{ab}$ & 73,0 abc \\
\hline $2,5 \mathrm{~min}$ & $74,0 \mathrm{a}$ & $1,5 \mathrm{bc}$ & 22,0 cde & $38,5 \mathrm{a}$ & $73,0 \mathrm{abc}$ \\
\hline $1 \mathrm{~min}$ & $82,5 \mathrm{a}$ & $1,5 \mathrm{bc}$ & $55,0 \mathrm{~b}$ & 29,5 a & $83,5 \mathrm{ab}$ \\
\hline \multicolumn{6}{|c|}{ Água temp. amb. } \\
\hline 48horas & $4,0 \mathrm{f}$ & $2,0 \mathrm{bc}$ & $12,0 \mathrm{e}$ & $17,5 \mathrm{~b}$ & 37,0 def \\
\hline 24horas & $12,0 \mathrm{def}$ & $2,0 \mathrm{bc}$ & $11,0 \mathrm{e}$ & $23,5 \mathrm{ab}$ & 36,5 ef \\
\hline 12horas & $6,5 \mathrm{f}$ & $2,0 \mathrm{bc}$ & $13,0 \mathrm{de}$ & $21,5 \mathrm{ab}$ & $34,5 \mathrm{f}$ \\
\hline \multicolumn{6}{|l|}{ Ác. sulfúrico } \\
\hline $10 \mathrm{~min}$ & $87,0 \mathrm{a}$ & $99,0 \mathrm{a}$ & 89,0 a & $0,0 \mathrm{~d}$ & $93,5 \mathrm{a}$ \\
\hline $5 \mathrm{~min}$ & $33,0 \mathrm{bc}$ & 98,5 a & $81,5 \mathrm{a}$ & $4,5 \mathrm{c}$ & $81,0 \mathrm{ab}$ \\
\hline $1 \mathrm{~min}$ & $21,5 \mathrm{~cd}$ & 98,5 a & $76,5 \mathrm{a}$ & $27,5 \mathrm{ab}$ & $47,5 \mathrm{cdef}$ \\
\hline \multicolumn{6}{|l|}{ Álcool etílico } \\
\hline $25 \mathrm{~min}$ & $47,0 \mathrm{~b}$ & $5,0 \mathrm{bc}$ & $30,0 \mathrm{~cd}$ & $27,0 \mathrm{ab}$ & $19,0 \mathrm{f}$ \\
\hline $10 \mathrm{~min}$ & $11,5 \mathrm{def}$ & $1,5 \mathrm{bc}$ & $31,5 \mathrm{c}$ & $27,0 \mathrm{ab}$ & $69,0 \mathrm{bcd}$ \\
\hline $5 \mathrm{~min}$ & $30,0 \mathrm{bcd}$ & $1,5 \mathrm{bc}$ & 16,0 cde & $25,5 \mathrm{ab}$ & 74,5 abc \\
\hline
\end{tabular}

${ }^{1} \mathrm{Na}$ mesma coluna, médias seguidas de letras iguais não diferem entre si pelo teste Tukey, a 5\%. 
a imersão em água a $80^{\circ} \mathrm{C}$ durante $1 \mathrm{~min}$, que resultou em $55 \%$ de germinação. A germinação da testemunha foi de apenas $10,5 \%$, que não diferiu de grande parte dos tratamentos.

Os melhores tratamentos para a quebra de dormência das sementes de angico-de-bezerro (Tab. 1) foram a imersão em água a $80^{\circ} \mathrm{C}$ durante 1 ou $2,5 \mathrm{~min}$ e a imersão em ácido sulfúrico concentrado durante $10 \mathrm{~min}$, com percentagens de germinação de $82,5 \%, 74,0 \%$ e $87,0 \%$, respectivamente. Souza et al. (1980), testando a germinação de Piptadenia obliqua (Pers.) Macbr., espécie muito próxima de $P$. moniliformis (Lewis 1987), também verificaram elevada percentagem de germinação após o tratamento das sementes com água quente, método que citaram como simples e econômico. A germinação da testemunha foi de apenas $5,5 \%$. Alguns tratamentos, apesar de não terem apresentado elevada taxa de germinação, tiveram algum benefício, resultando em percentagens de germinação variando de $21,5 \%$ a $47,0 \%$, superiores, portanto, à testemunha.

Nas sementes nuas de sabiá, os tratamentos que resultaram em maiores percentagens de germinação, não diferindo entre si, foram: imersão em água a $80^{\circ} \mathrm{C}$ (nos três períodos testados), imersão em ácido sulfúrico concentrado nos períodos de 5 e 10 min e imersão em álcool etílico por $5 \mathrm{~min}$, com percentuais de germinação variando de $73,0 \%$ a $93,5 \%$ (Tab. 1). Os demais tratamentos não diferiram da testemunha.

Nos artículos de sabiá, os percentuais de germinação nos melhores tratamentos não diferiram do observado na testemunha $(31,5 \%)$. Portanto, nenhum dos tratamentos teve efeito sobre a quebra da dormência. Nos tratamentos com ácido sulfúrico durante 5 e $10 \mathrm{~min}$, os percentuais de germinação $(4,5 \%$ e $0,0 \%$, respectivamente) foram inferiores ao da testemunha, o que parece contraditório, uma vez que esses tratamentos incluíram-se entre os melhores para as sementes nuas. A redução da germinação em relação à testemunha não ocorreu com nenhuma outra espécie ou tratamento.

Lorenzi (1992) cita 50\% de germinação para as sementes ou artículos de sabiá, sem qualquer tratamento. Este percentual é bem maior do que os obtidos neste trabalho, em sementes não tratadas. Apesar dos percentuais de germinação mais altos verificados nas sementes nuas de sabiá, dada a dificuldade de retirá-las do interior dos artículos, o mais prático seria a semeadura destes. Essa recomendação aplica-se principalmente quando a quantidade de artículos não for limitante, pois a densidade de semeadura deveria ser aumentada, na expectativa de aproximadamente $30 \%$ de germinação (percentual obtido na testemunha).

Ao final dos 15 dias de teste, as sementes não germinadas de bordão-de-velho e de angicode-bezerro e os artículos de sabiá não apresentaram danos decorrentes dos tratamentos, não se evidenciando alterações de tamanho ou de rigidez do tegumento. Nessas espécies, a média de descarte (sementes em início de decomposição) durante o teste foi de 1 a $2 \%$ por tratamento, o que não indica, necessariamente, efeito de tratamento. Entretanto, as sementes de pau-ferro foram muito danificadas pelo tratamento em água a $80^{\circ} \mathrm{C}$, havendo descarte de $45 \%, 78 \%$ e $90,5 \%$ das sementes, correspondendo aos períodos de tratamento de $1,2,5$ e $5 \mathrm{~min}$, respectivamente. As sementes nuas de sabiá ficaram mais vulneráveis a danos que os artículos. Nos tratamentos com água à temperatura ambiente e ácido sulfúrico concentrado, a percentagem de sementes mortas variou de 5 a $7,5 \%$; o tratamento com álcool durante $25 \mathrm{~min}$ também teve efeito negativo, resultando na morte de $12,5 \%$ das sementes. Os maiores danos foram observados nos tratamentos com água a $80^{\circ} \mathrm{C}$, que resultaram no descarte de $10 \%, 22 \%$ e $20 \%$ das sementes, correspondendo aos períodos de tratamento de $1,2,5$ e $5 \mathrm{~min}$, respectivamente.

As Fig. 1, 2, 3, 4 e 5 ilustram a germinação diária das sementes das testemunhas e dos tratamentos que resultaram em maior germinação total das sementes de pau-ferro, artículos de sabiá, bordão-de-velho, sementes nuas de sabiá e angicode-bezerro, respectivamente.

Nas sementes de pau-ferro e nos artículos de sabiá, a germinação ocorreu de maneira lenta, alongando-se até ao $15^{\circ}$ dia do teste, com baixos 


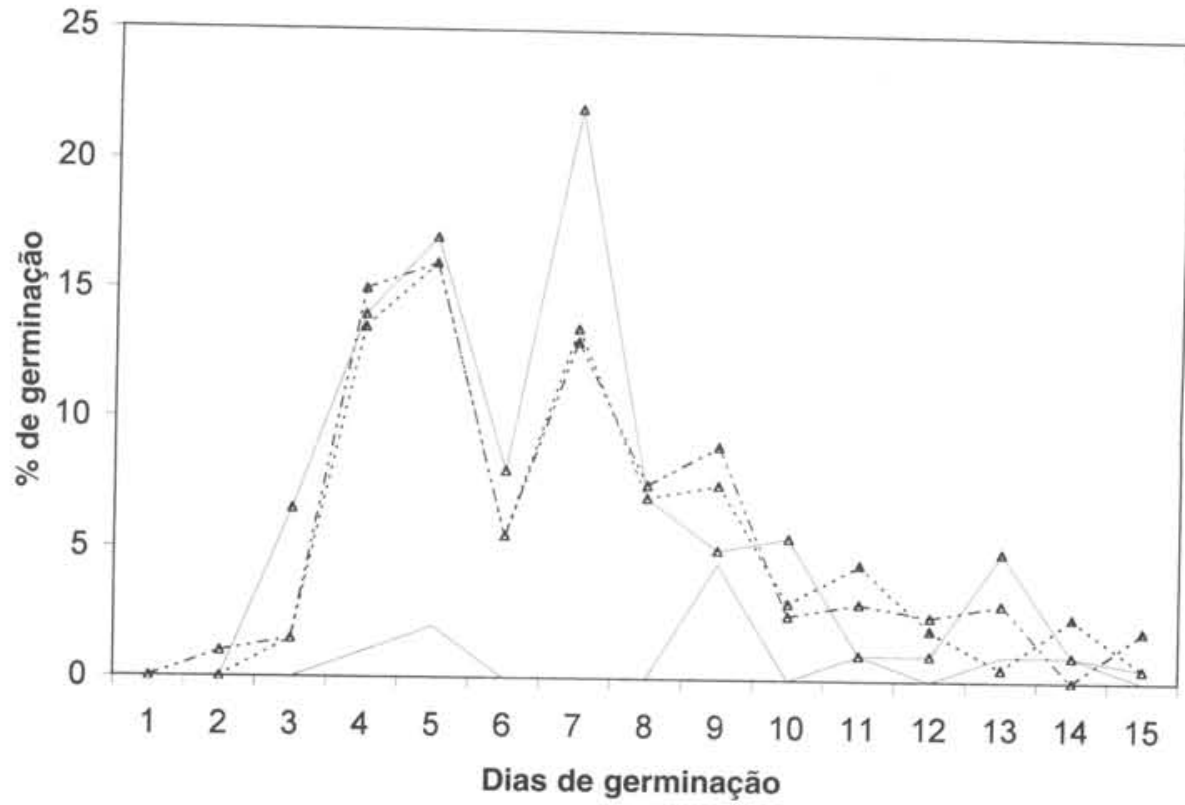

Figura 1. Germinação diária das sementes de Caesalpinia ferrea Mart. ex. Tul. (pau-ferro) nos tratamentos de maior germinação total e na testemunha. Testemunha ——; Imersão em ácido sulfúrico durante $1 \mathrm{~min} \cdots-\triangle_{-\cdots}-$; Imersão em ácido sulfúrico durante 5 min $\cdots \Delta \cdots$ : Imersão em ácido sulfúrico durante $10 \mathrm{~min} \longrightarrow \Delta$

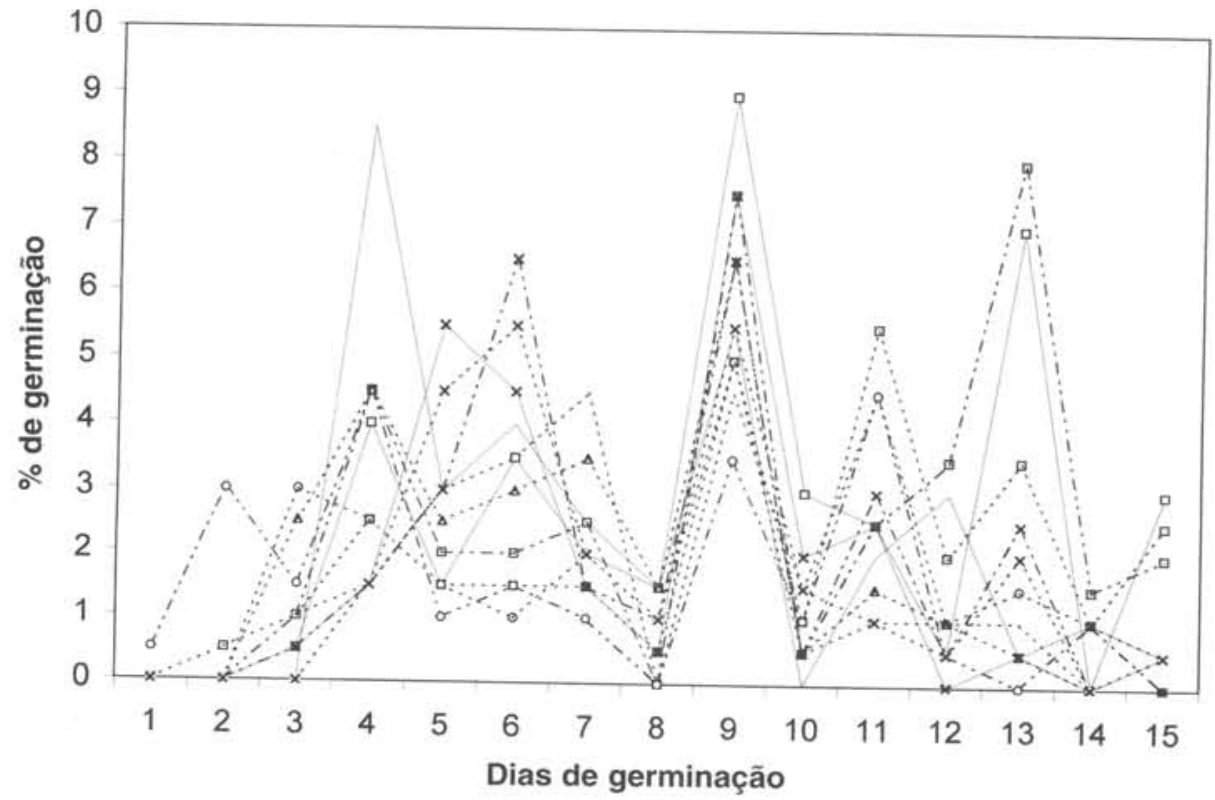

Figura 2. Germinação diária dos artículos de Mimosa caesalpiniifolia Benth. (sabiá) nos tratamentos de maior germinação total e na testemunha. Testemunha —_ ; Lixa -....-.; Imersão em água à temperatura ambiente durante 12 horas ... - O - . ; Imersão em água

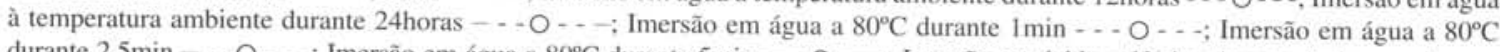

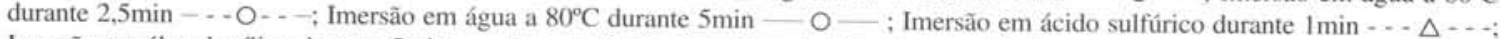

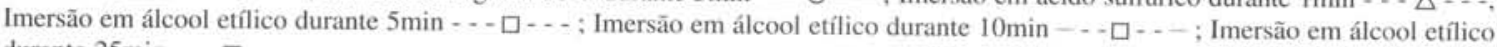
durante $25 \mathrm{~min}-\square-$ 


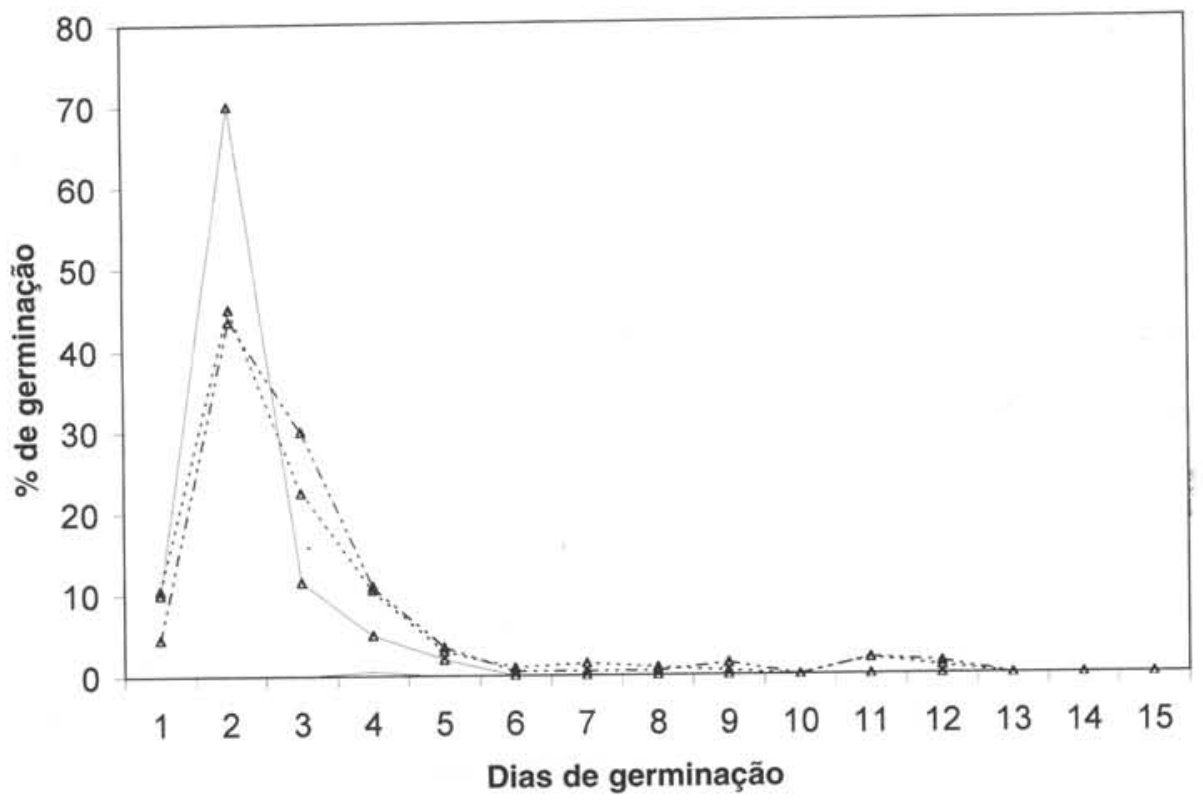

Figura 3. Germinação diária das sementes de Samanea saman (Jacq.) Merr. (bordão-de-velho) nos tratamentos de maior germinação total e na testemunha. Testemunha ——; Imersão em ácido sulfúrico durante $1 \mathrm{~min} \mathrm{-} \mathrm{-} \Delta$ - ..; Imersão em ácido sulfúrico durante $5 \mathrm{~min}-\cdots \Delta \cdots$ - Imersão em ácido sulfúrico durante $10 \mathrm{~min}-\Delta-$

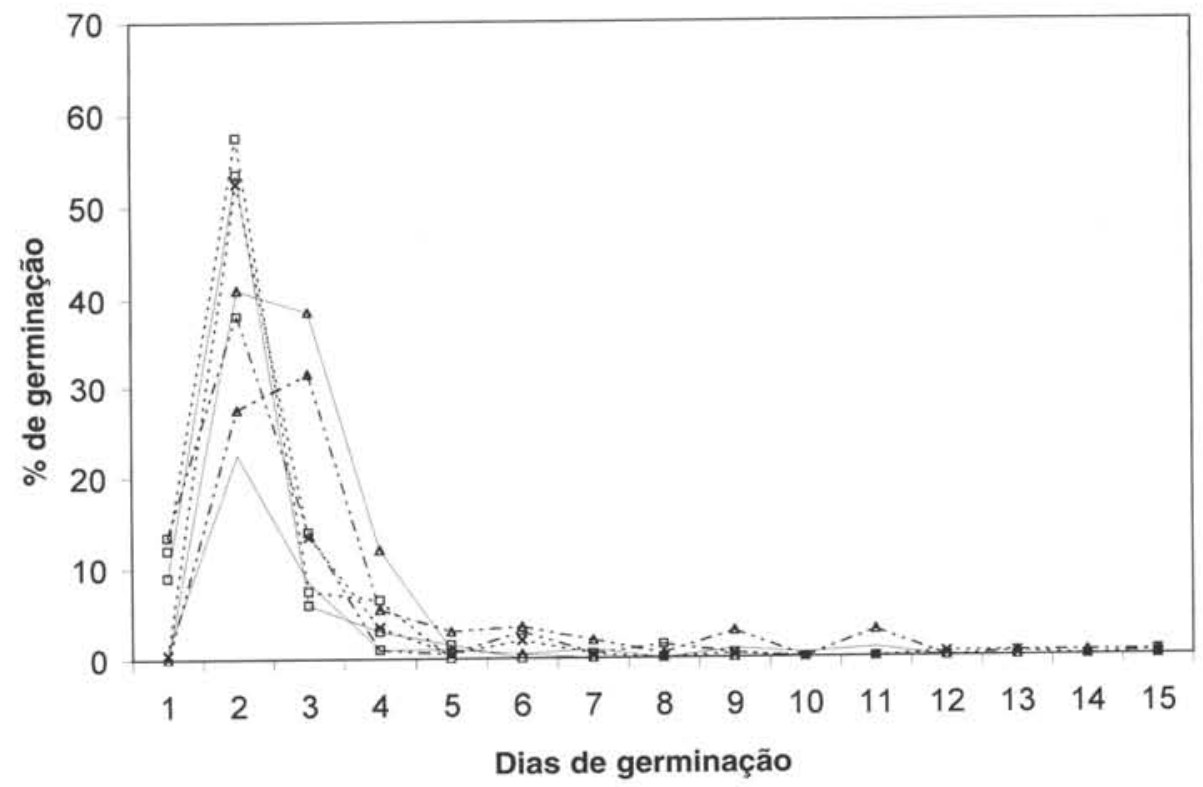

Figura 4. Germinação diária das sementes nuas de Mimosa caesalpiniifolia Benth. (sabiá) nos tratamentos de maior germinação total e na testemunha. Testemunha —_ : Imersão em água a $80^{\circ} \mathrm{C}$ durante $1 \mathrm{~min}$ - . - O - - - Imersão em água a $80^{\circ} \mathrm{C}$ durante $2,5 \mathrm{~min}$

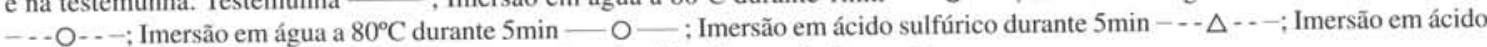
sulfúrico durante $10 \mathrm{~min} \longrightarrow \Delta \longrightarrow$; Imersão em álcool etílico durante $5 \mathrm{~min}$ - . - $\square$ - . - 


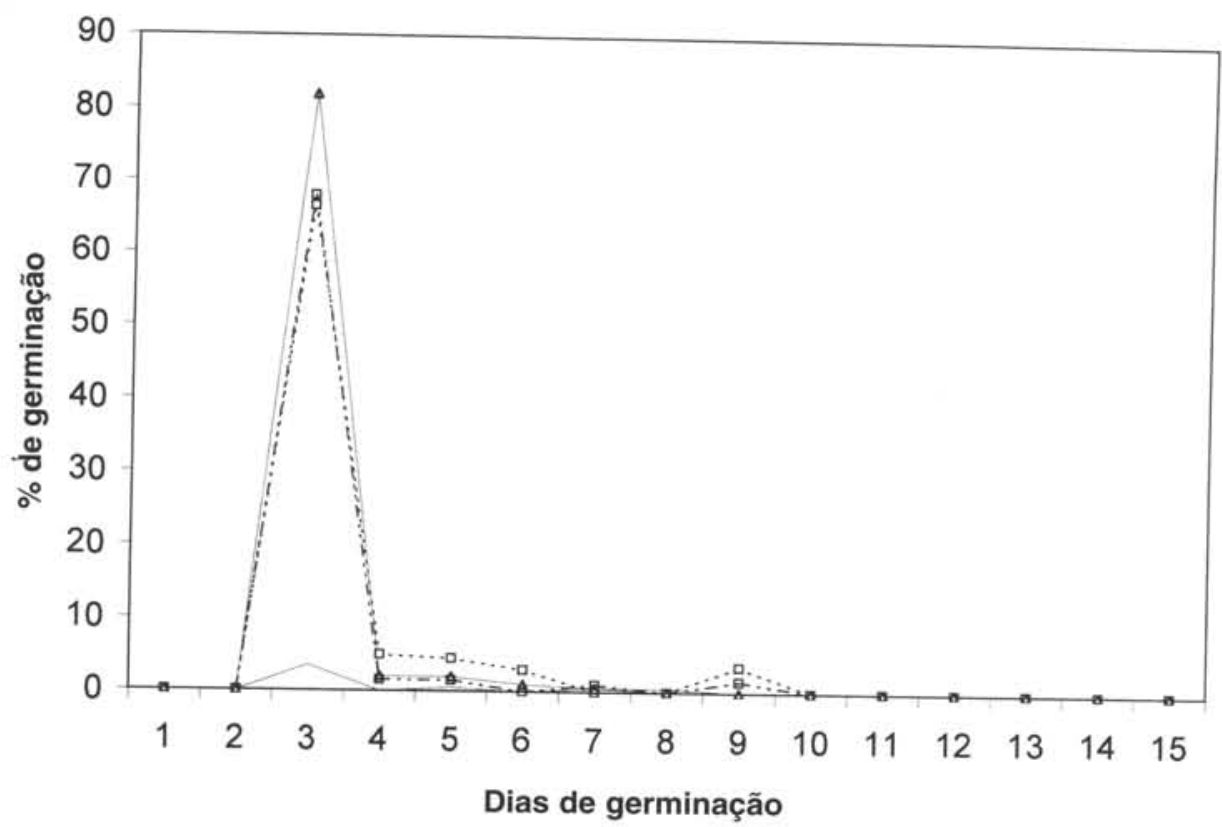

Figura 5. Germinação diária das sementes de Piptadenia moniliformis Benth. (angico-de-bezerro) nos tratamentos de maior germinação total e na testemunha. Testemunha _—; Imersão em água a $80^{\circ} \mathrm{C}$ durante $1 \mathrm{~min} \ldots-\ldots \ldots$ - - Imersão em água a $80^{\circ} \mathrm{C}$ durante $2,5 \mathrm{~min}$ -...- Imersão em ácido sulfúrico durante $10 \mathrm{~min}-\Delta$

percentuais diários. Nos artículos de sabiá, as percentagens diárias foram sempre inferiores a $10 \%$. Nas sementes de pau-ferro, apesar dos reduzidos percentuais, germinação diária em torno de $15-20 \%$ foi constatada do quarto ao sétimo dia do teste.

Germinação a partir do primeiro dia de teste foi constatada nas sementes de bordão-de-velho e nas sementes nuas de sabiá. Nestas, destacaramse os tratamentos com água a $80^{\circ} \mathrm{C}$, com percentagens de germinação de 9 a $13,5 \%$ nas primeiras $24 \mathrm{~h}$ de teste e cerca de $90 \%$ do total sementes germinadas até ao terceiro dia. As sementes de bordão-de-velho também tiveram elevada germinação nos primeiros dias de teste, ou seja, 80 a $90 \%$ das sementes germinaram até ao terceiro dia.

Nas sementes de angico-de-bezerro houve grande concentração de germinação ao terceiro dia do teste, chegando a $82 \%$ no tratamento com ácido sulfúrico durante 10min Após esse dia, a germinação diária foi inferior a $5 \%$ e nenhuma germinação foi observada após o nono dia do teste.
Em relação às testemunhas, destacaram-se os percentuais relativamente elevados de germinação diária das sementes nuas de sabiá, cujo somatório, ao quarto dia, foi de $33 \%$, percentual praticamente igual àquele verificado ao final dos 15 dias de teste. Nos artículos de sabiá, a germinação diária, apesar de bem menor que a verificada nas sementes nuas, destacou-se em relação às das demais espécies, cujos percentuais diários mais comumente observados foram $0,0,5$ e $1 \%$.

Os dados de velocidade de germinação (Tab. 2) estão estreitamente relacionados com os de germinação total. Isto é, os tratamentos que resultaram em maiores percentuais de germinação também apresentaram maior rapidez de germinação. As correlações entre as duas variáveis foram de 0,$99 ; 0,99 ; 0,93 ; 0,84$; e 0,75 , respectivamente, para as sementes de angico-de-bezerro, bordão-de-velho, pau-ferro, sabiá (com artículo) e sabiá (sementes nuas). Conforme discutido por Alvarez Rangel (1984), a dureza do tegumento é simples barreira física que, uma vez rompida, resulta em rápida germinação. 
Tabela 2. Velocidade de germinação das sementes de leguminosas ${ }^{1}$

\begin{tabular}{|c|c|c|c|c|c|}
\hline Tratamento & Angico-de-bezerro & Bordão-de-velho & Pau-Ferro & Sabiá (artículo) & Sabiá (semente nua) \\
\hline Testemunha & $0,9 \mathrm{e}$ & $0,1 \mathrm{c}$ & $0,7 \mathrm{~d}$ & $2,6 \mathrm{a}$ & $8,5 \mathrm{bc}$ \\
\hline Lixa 2,3 de & $0,6 \mathrm{c}$ & $1,6 \mathrm{~cd}$ & $2,0 \mathrm{ab}$ & $14,4 a b c$ & \\
\hline \multicolumn{6}{|l|}{$\begin{array}{l}\text { Lixa } 2,3 \text { de } \\
\text { Água } 80^{\circ} \mathrm{C}\end{array}$} \\
\hline $2,5 \mathrm{~min}$ & $\begin{array}{l}11,8 \mathrm{a} \\
2,3 \mathrm{de}\end{array}$ & $0,0 \mathrm{c}$ & $0,5 \mathrm{~d}$ & $\begin{array}{l}2,4 \mathrm{a} \\
2,5 \mathrm{a}\end{array}$ & $\begin{array}{l}19,4 \mathrm{ab} \\
19,2 \mathrm{ab}\end{array}$ \\
\hline $1 \mathrm{~min}$ & $12,6 \mathrm{a}$ & $\begin{array}{l}0,1 \mathrm{c} \\
0,1 \mathrm{c}\end{array}$ & $\begin{array}{l}1,3 \mathrm{~cd} \\
3,6 \mathrm{bc}\end{array}$ & $1,9 \mathrm{ab}$ & $\begin{array}{l}19,2 \mathrm{ab} \\
22,4 \mathrm{a}\end{array}$ \\
\hline \multicolumn{6}{|c|}{$\begin{array}{l}1 \text { min } \\
\text { Água temp.amb. }\end{array}$} \\
\hline 48horas & $0,4 \mathrm{e}$ & $1,0 \mathrm{c}$ & $3,1 \mathrm{~cd}$ & 2,9 a & $16,4 a b$ \\
\hline 24horas & $1,6 \mathrm{e}$ & $0,5 \mathrm{c}$ & $1,3 \mathrm{~cd}$ & $2,6 \mathrm{a}$ & $13,8 \mathrm{abc}$ \\
\hline 12 horas & $0,8 \mathrm{e}$ & $0,6 \mathrm{c}$ & $1,7 \mathrm{~cd}$ & $2,4 \mathrm{a}$ & $14,4 \mathrm{abc}$ \\
\hline \multicolumn{6}{|l|}{$\begin{array}{l}\text { 12horas } \\
\text { Ác. sulfúrico }\end{array}$} \\
\hline $10 \mathrm{~min}$ & $14,1 \mathrm{a}$ & $25,3 \mathrm{a}$ & $7,9 \mathrm{a}$ & $0,0 \mathrm{c}$ & $18,3 \mathrm{ab}$ \\
\hline $5 \min$ & $4,5 \mathrm{~cd}$ & $20,2 \mathrm{~b}$ & $7,2 \mathrm{a}$ & $0,3 b c$ & $14,0 a b c$ \\
\hline $1 \mathrm{~min}$ & 2,7 cde & $22,3 \mathrm{~b}$ & $6,3 \mathrm{ab}$ & $2,3 \mathrm{a}$ & $9,6 \mathrm{abc}$ \\
\hline Alcool etílico & . & & & & \\
\hline $25 \mathrm{~min}$ & $7,5 \mathrm{~b}$ & $0,8 \mathrm{c}$ & $3,7 \mathrm{bc}$ & $1,9 \mathrm{ab}$ & $2,7 \mathrm{c}$ \\
\hline $10 \mathrm{~min}$ & $1,8 \mathrm{e}$ & $0,1 \mathrm{c}$ & $2,8 \mathrm{~cd}$ & $2,0 \mathrm{ab}$ & $18,6 \mathrm{ab}$ \\
\hline $5 \min$ & $4,8 \mathrm{c}$ & $0,0 \mathrm{c}$ & $1,5 \mathrm{~cd}$ & $1,9 a b$ & $17,0 \mathrm{ab}$ \\
\hline
\end{tabular}

' Na mesma coluna, médias seguidas de letras iguais não diferem entre si pelo teste Tukey, a $5 \%$.

Os artículos de sabiá tiveram velocidades de germinação bem inferiores àquelas das sementes nuas (Tab. 2). Na testemunha, apesar dos percentuais de germinação terem sido próximos, $38,0 \%$ nas sementes nuas e $31,5 \%$ nos artículos, as respectivas velocidades de germinação foram 8,5 e 2,6. Supõe-se que, nos artículos, a velocidade de embebição da água pelas sementes foi reduzida pela presença de mais uma camada de revestimento.

Com exceção dos artículos de sabiá, para os quais nenhum tratamento foi eficiente, o uso da ácido sulfúrico durante $10 \mathrm{~min}$ resultou em elevadas percentagens de germinação das sementes. Para bordão-de-velho e pau-ferro, o tempo de tratamento das sementes pode ser reduzido a $1 \mathrm{~min}$, sem prejuízo de germinação. Entretanto, considerando-se o elevado custo do ácido sulfúrico e os perigos envolvidos no seu manuseio, seria preferível, exceto para bordão-develho, a imersão das sementes em água a $80^{\circ} \mathrm{C}$. Neste caso, o tempo de tratamento mais adequado depende da espécie a ser tratada. No caso de pauferro, a substituição do tratamento só seria recomendável caso fosse possível dobrar a taxa de semeadura.

\section{Agradecimentos}

Ao CNPq, pela concessão de Bolsa à segunda Autora.

\section{Referências bibliográficas}

Alvarez Rangel, R. 1984. Caracterizacion de los mecanismos de controle de la latencia y germinacion de las semillas de Parkinsonia aculeata L. 1. Respuestas de las semillas a los tratamientos para romper latencia y sus implicaciones ecologicas. Revista de la Facultad de Agronomía 13(14): 5-30.

Antônio, F. G.; Penteado, M. I. O. \& Seiffert, N. F. 1985. Recomendações para a quebra de dormência em sementes de Galactia spp. Comunicado técnico EMBRAPA-CNPGC, Campo Grande.

Barbosa, E.; Silva, M. M.; Rocha, F. R.; Queiroz, L .P. \& Crepadi, I. C. 1996. Ensaios de germinação em Leguminosae da Caatinga. Resumos XLVII Congresso Nacional de Botânica. Nova Friburgo: Sociedade de Botânica do Brasil, Nova Friburgo.

Bewley, J. D. \& Black, M. 1994. Seeds: physiology of development and germination. $2^{\text {ed }}$ Ed. Plenum, New York.

Demel, T. \& Demel, T. 1994. Germination ecology of two endemic multipurpose species of Erythrina from Ethiopia. Forest Ecology and Management 65(2-3): 81-87.

Duarte, M. J. 1978. Análise de sementes de seis espécies autóctones e alternativas para o reflorestamento na região semi-árida do Nordeste Brasileiro. Dissertação de Mestrado. Universidade Federal do Paraná, Curitiba. 
Dutra, A. S. R.; Castro, J. R.; Souza, R. P. \& Ribeiro, M. C. C. 1994. Superação de dormência em sementes de jucá. Resumos da XVIII Reunião Nordestina de Botânica. Universidade Federal da Paraíba, Areia.

Kondo, T. 1993. Promotion of hard-seed germination in Lotus corniculatus var. japonicus for use in amenity grasslands. Seed Science and Technology 21(3): 611-619.

Lorenzi, H. 1992. Árvores brasileiras: manual de identificação e cultivo de plantas arbóreas nativas do Brasil. Ed. Plantarum, Nova Odessa.

Lewis, G. P. 1987. Legumes of Bahia. Royal Botanic Gardens, Kew.

Monte, M. J. S.; Branco, A. C. L. C. \& Gouveia, F. M. A. 1995. Influência do processo de escarificação com ácido sulfúrico na germinação de sementes de Dimorphandra gardneriana Tul. "fava-d'anta". Resumos da XIX Reunião Nordestina de Botânica. Sociedade de Botânica de Brasil, Recife.

Popinigis, F. 1977. Fisiologia da semente. Ministério da Agricultura/Agiplan, Brasília.

Rodrigues, E. H. \& Aguiar, I. B. \& Sader, R. 1990. Quebra de dormência de sementes de três espécies do gênero Cassia. Revista Brasileira de Sementes 12(2): 17-27.
Sabiiti, E. N. 1983. Ecological studies on Macroptilium atropurpureum Urb. in Rwenzori National Park, Uganda. 1. Effects of pre-treating seeds with concentrated sulphuric acid, scarification, boiling and burning on germination. African Journal of Ecology 4(21): 285-289.

Shelton, H. M. 1994. Establishment of forage tree legumes. Pp. 132-142. In R. C. Gutterid \& H. M. Shelton (Ed.) Forage tree legumes in tropical agriculture. $\mathrm{CAB}$ International, Wallingford.

Skerman, P. J. 1977. Tropical forage legumes. 2 ed., FAO Plant Production and Protection, Rome.

Souto, M. S. 1996. Caracteres morfológicos de frutos e sementes (poder germinativo) e crescimento de plantas jovens de Leguminosae da caatinga de Alagoinha, PE. Dissertaçâo de Mestrado. Universidade Federal Rural de Pernambuco, Recife.

Souza, S. M.; Drumond, M. A. \& Silva, H. D. 1980. Estudos de métodos para superar a dormência de sementes de Piptadenia obliqua (Pers) Macbr., Pithecellobium parvifolium (Willd.) Benth. e Cassia excelsa Schard. EMBRAPA-CPATSA, Petrolina. 